\title{
How Teacher Characteristics Relate to How Teachers Use Dashboards: Results from Two Case Studies in K-12
}

\author{
Anouschka van Leeuwen ${ }^{1}$, Carolien A. N. Knoop-van Campen², Inge Molenaar ${ }^{3}$, \\ Nikol Rummel ${ }^{4}$
}

\begin{abstract}
Teacher dashboards are a specific form of analytics in which visual displays provide teachers with information about their students; for example, concerning student progress and performance on tasks during lessons or lectures. In the present paper, we focus on the role of teacher dashboards in the context of teacher decision-making in $\mathrm{K}-12$ education. There is large variation in teacher dashboard use in the classroom, which could be explained by teacher characteristics. Therefore, we investigate the role of teacher characteristics - such as experience, age, gender, and self-efficacy - in how teachers use dashboards. More specifically, we present two case studies to understand how diversity in teacher dashboard use is related to teacher characteristics. Surprisingly, in both case studies, teacher characteristics were not associated with dashboard use. Based on our findings, we propose an initial framework to understand what contributes to diversity of dashboard use. This framework might support future research to attribute diversity in dashboard use. This paper should be seen as a first step in examining the role of teacher characteristics in dashboard use in $\mathrm{K}-12$ education.
\end{abstract}

\section{Notes for Practice}

- Teacher dashboards are a specific application of learning analytics in which visual displays provide teachers with information about their students; for example, concerning student progress and performance on tasks during lessons or lectures.

- In the two case studies presented here, teacher dashboard use in $\mathrm{K}-12$ does not seem to be related to the teacher's age, gender, years of teaching experience, or technological self-efficacy.

- A framework to guide future work for understanding the relationship between teacher characteristics and teacher dashboard use is presented.

\section{Keywords}

Teacher dashboards, teacher characteristics, K-12

Submitted: 17/08/20 — Accepted: 17/04/21 — Published: 03/09/21

Corresponding author ${ }^{1} E$ mail: a.vanleeuwen@uu.nl Address: Utrecht University, Department of Education, Heidelberglaan 1, 3584CS, Utrecht, the Netherlands. ORCID ID: https://orcid.org/0000-0003-2970-1380

${ }^{2}$ Email: c.knoop-vancampen@pwo.ru.nl Address: Radboud University, Montessorilaan 3, 6525 HR Nijmegen, The Netherlands. ORCID ID: https://orcid.org/0000-0002-3666-8577

${ }^{3}$ Email: i.molenaar@pwo.ru.nl Address: Radboud University, Montessorilaan 3, 6525 HR Nijmegen, The Netherlands. ORCID ID: https://orcid.org/0000-0003-4639-2524

${ }^{4}$ Email: nikol.rummel@rub.de Address: Ruhr Universität Bochum, Institut für Erziehungswissenschaft, Universitätsstraße 150, D-44801

Bochum, Germany. ORCID ID: https://orcid.org/0000-0002-3187-5534

\section{Introduction}

Learning analytics are used increasingly in educational practices. Many learning technologies applied in $\mathrm{K}-12$ facilitate the automatic collection of data about learners who use computers to practise skills or to collaborate. These systems often include some kind of direct feedback loop to the student; for example, by adjusting the difficulty level of the task the student is working on. Simultaneously, the collected information is fed back to the teacher who may use this information to improve their teaching. Teacher dashboards are a specific application of learning analytics in which visual displays provide teachers with information about their students; for example, concerning student progress and performance on tasks during lessons or lectures (Verbert et al., 2014). Teacher characteristics such as experience, age, gender, and self-efficacy may influence how teachers use 
dashboards (Venkatesh et al., 2003). In the present paper, we present two case studies to improve our understanding of how teachers use dashboards and how teacher characteristics relate to this use.

\subsection{Models of How Teachers Use Dashboards}

Teacher dashboards provide concurrent information about student abilities, progress, performance, and errors made during lessons (Verbert et al., 2014). The data that serves as input for teacher dashboards is derived from learning technologies used for individual or collaborative practice of knowledge and skills. Usually, such learning technologies in $\mathrm{K}-12$ education automatically collect data about learners. An extensive body of research has focused on using these data to facilitate a direct feedback loop to the student; for example, by adjusting the difficulty level of the task the student is working on (Aleven, McLaughlin, Glenn, \& Koedinger, 2016). Increasingly, the focus is on how the collected data can also serve to provide teachers with information about their students (Van Leeuwen, Janssen, Erkens, \& Brekelmans, 2015). Both ways of enhancing education - either by the direct student feedback loop or by informing the teacher — can be considered as applications of learning analytics, a field defined as "the measurement, collection, analysis and reporting of data about learners and their contexts, for purposes of understanding and optimizing learning and the environments in which it occurs" (Siemens \& Gašević, 2012, p. 1).

In this article, we consider a specific application of learning analytics to serve teachers, namely teacher dashboards. Teacher dashboards are visual displays that provide teachers with information about their students (Verbert et al., 2014). Teacher dashboards may be provided for different purposes and at different time points in pedagogical practice. An important distinction is whether the dashboard is used in-class during student-teacher interaction for immediate decision-making, or in between classroom sessions to support, for example, teacher reflections or teacher planning of subsequent classroom sessions (Wise \& Jung, 2019). In this paper, we focus on the first situation, when teachers have access to dashboards during class, with the dashboard displaying real-time information about students. The goal of the dashboard is therefore to support teachers' decision-making as students are working on a task; for example, concerning which students need support and what type of support is needed. This specific situation has implications for dashboard requirements in terms of design and usability. The case studies we will present in this paper are both situated in mathematics education. As decision-making takes place in the fast-paced, dynamic classroom, many authors have argued for a human-centred design of the dashboard, taking the specific context and requirements into account (Buckingham Shum, Ferguson, \& Martinez-Maldonado, 2019). Following this literature, the two dashboards we will describe were both developed through a co-design process with teachers. We will focus on the process of how teachers use the dashboards for their decision-making in this specific context.

Various authors have proposed theoretical models to describe how teachers translate information on the dashboard into action. Most models distinguish different phases that teachers go through from the moment they look at a teacher dashboard, to the resulting pedagogical action (Van Leeuwen, Rummel, \& van Gog, 2019; Molenaar \& Knoop-van Campen, 2019; Wise \& Jung, 2019). In the work by Van Leeuwen et al. (2019), teachers' use of dashboards is based on the teacher noticing framework (Van Es \& Sherin, 2002). Applied to the context of teacher dashboards, this framework describes that teachers first need to detect or identify relevant events based on the information displayed on the dashboard, followed by interpretation of those events, ultimately leading to a decision for pedagogical action. An equivalent model developed by Wise and Jung (2019) consists of a sense-making phase, in which teachers generate questions that lead to investigation and interpretation of the dashboard, followed by pedagogical responses. Finally, the model underlying the study by Molenaar and Knoop-van Campen (2019) consists of an awareness stage (which data is available), a reflection stage (which question can the teacher answer based on the data), a sense-making stage (answering the question based on the data), and the impact stage, in which a decision for pedagogical action is made.

Comparing these theoretical models, several recurring elements are summarized here into three overarching phases. First, all models contain an initial stage of awareness, meaning that teachers know there is data available and they look at the information shown on the dashboard. Teachers can be looking for information, or driven by the analytics themselves, when the teacher notices or is alerted to a deviant situation and decides to inspect the dashboard in more detail. The second stage is interpretation, in which the teacher engages in making sense of the analytics shown, and arrives at an answer to the following question: What are the analytics telling me? The final stage is enactment, in which interpretation is translated into pedagogical action. This could entail a support action for students, but a teacher can also decide not to undertake an action, or to reflect on their own actions instead of student behaviours.

When the teacher decides to offer students feedback based on the information on the dashboard, several types of feedback can be distinguished, namely process, metacognitive, task, social, and personal feedback (Van den Bergh, Ros, \& Beijaard, 2013; Hattie \& Timperley, 2007). Some types of teacher feedback are considered more effective than others. Process and metacognitive feedback, which support student regulation and strategic handling, are proven to be most effective (de Jager, Jansen, \& Reezigt, 2005; Hattie, 2012; Hattie \& Timperley, 2007). Also, task feedback, which is directly related to the current performance and understanding, is helpful for students (Butler \& Winne, 1995; Hattie \& Timperley, 2007). Social and personal 
feedback are considered less effective since they do not link student behaviour to task or process elements (Shute, 2008). Yet in a collaborative setting, social feedback can be very supportive in managing group processes and therefore contributing to learning gains (Van Leeuwen \& Janssen, 2019).

Empirical studies show, in line with the assumptions of the models explained above, that teachers use information about their students to adapt their instruction and feedback practices to student needs (Molenaar \& Knoop-van Campen, 2017a; Verbert et al., 2014). When teachers incorporate dashboards into their daily routines, they can benefit from the additional knowledge provided. Learning analytics enhance teacher awareness and interpretation of student needs for support (Melero et al., 2015; Schwarz \& Asterhan 2011; Xhakaj, Aleven, \& McLaren, 2017). In turn, teachers are enabled to make informed decisions for pedagogical action; for instance, in deciding which student activities to react to, or by supporting teachers to select more effective forms of feedback (Molenaar \& Knoop-van Campen, 2019). There are even first indications that increased teacher dashboard use is associated with changes in teacher behaviour that enhances student performance (MartinezMaldonado et al., 2014).

While research thus shows positive results of dashboard use on teacher practices, research has also shown considerable variation in how often and in what ways teachers use dashboards. Concerning the awareness and interpretation stages, it was, for example, found that teachers interpreted the same information in different ways (Van Leeuwen, Janssen, Erkens, \& Brekelmans, 2014), and that the type of information that teachers select to look at on dashboards varies (Van Leeuwen et al., 2019). Similarly, other research demonstrated large diversity in how often teachers consulted dashboards, whether they were able to translate this information into pedagogical action (Herodotou, Rienties, Boroowa, Zdrahal, \& Hlosta, 2019), and if so, what kind of pedagogical action they selected (Molenaar \& Knoop-van Campen, 2019). Of course, the way teachers use a dashboard also depends on the kind of information displayed and to what extent the dashboard fulfills a role in supporting the teacher to become aware of and interpret relevant information (Sergis \& Sampson, 2017). Even so, Van Leeuwen et al. (2019) found that within several experimental groups in which dashboards with different functionalities were investigated, the withingroup variation was considerable.

Also, in classroom research where similar dashboards are used, great diversity in how teachers use dashboards has been found (Molenaar \& Knoop-van Campen, 2019). Teachers differ in the extent to which they consult a dashboard, in how they interpret information on a dashboard, and in what kinds of actions they connect to their consultation of the dashboard. Given the affordances of dashboards to support teachers (and thereby students), it is important to examine how this variation in teacher dashboard use can be explained. One potential direction to take in explaining this variation is by considering teacher dashboards as a novel piece of technology in the classroom. As for all technological innovations in education, teacher dashboards can be regarded as a new instrument that teachers need to master in order to successfully connect it to their existing routines (Hutchins, 2000). Such mastery can occur as a result of professional development activities such as trainings, or as a result of gaining more experience by implementing the technology into daily practice (Rienties, Herodotou, Olney, Schencks, $\&$ Boroowa, 2018). Whether or not teachers are able to use technology successfully thus may depend on teacher characteristics related to this learning process, such as their amount of experience with technology and their acquired technological proficiency. While there is a wealth of literature on teacher characteristics in relation to technology use in a wider sense (Venkatesh et al., 2003), there is much less on the role of teacher characteristics concerning use of dashboards. We will, therefore, describe the most prominent work on teacher use of technology in a more general sense, and try to relate that work to the case of teacher dashboards.

\subsection{The Role of Teacher Characteristics}

Concerning teacher use of technology in a broader sense, Venkatesh and colleagues (2003) summarized and synthesized eight prevalent theories to arrive at the Unified Theory of Acceptance and Use of Technology (UTAUT). As the name of that theory implies, it is good to immediately make a distinction here between theories aimed at explaining acceptance of technology, as opposed to theories aimed at explaining actual use of technology. The case studies presented here are aimed at the latter, since we focus on situations where teachers have already chosen to make use of dashboards and the required facilities are already in place. Following the UTAUT model (Venkatesh et al., 2003), the following teacher characteristics are assumed to be associated with technology use: gender, age, and experience with the technology under study. These factors are shown to relate to technology use, although empirical studies often demonstrate mixed findings concerning the question of whether these factors relate positively or negatively to technology use. For example, concerning gender, female teachers are often found to experience lower levels of confidence in their technological proficiency than male teachers, and therefore to use technology to a lesser extent (e.g., Lin et al., 2013). In other studies, however, these findings are not replicated (e.g., Teo, 2010; Wong et al., 2012).

Similarly, findings concerning the relation between teacher age and use of technology are not consistent. As Mueller and colleagues (2008) describe, on the one hand, younger teachers generally display higher levels of technological proficiency, which makes them more likely to introduce technology into their classrooms. On the other hand, younger teachers generally 
have less teaching experience and therefore struggle more with developing such pedagogical skills as classroom management. As Mueller and colleagues put it, "Even though their experiences with computer technology may be limited, more experienced teachers may have the time and resources to explore an innovation such as computer technology and apply it to their developed curriculum" (p. 1533).

A complicating factor is thus that teacher characteristics cannot be considered on their own, but influence each other in the resulting use of technology, as in the case of age, teaching experience, and technological proficiency. We therefore hypothesize that the same teacher characteristics could play a role in explaining teacher dashboard use, but do not pose any hypotheses about whether this may be a positive or negative relationship. Based on the UTAUT model and the studies described above, we include the following teacher characteristics to explain their use of dashboards: gender, age, teaching experience, experience with the specific technology, and technological proficiency.

\subsection{The Present Article}

The main goal of the present article is to explore the role of teacher characteristics for variations in their use of dashboards. To do so, we report on two case studies investigating how teachers used the dashboard (awareness, interpretation, and enactment phases), and then address the association between dashboard use and teacher characteristics. The two case studies investigated dashboard use in different contexts. The first (study A) is an experimental study into how dashboards inform teachers about students' collaborative learning activities. We examine whether the function of the dashboard as well as whether teacher characteristics influence how they evaluate the situation. The second (study B) is a classroom study into how dashboards inform teachers about student performance and progress. It addresses how teachers translate dashboard information into individual feedback during math classes. Each case study assesses the variations in how teachers use dashboards covering different phases of the theoretical model: case study A focuses on the awareness and interpretation stages by analyzing how teachers consult the dashboard information and what interpretations they derive, whereas case study B addresses the awareness and enactment stages, investigating how the dashboard information drives their feedback actions.

This work is a first attempt to explain variance in how teachers use dashboards using teacher characteristics such as age, teaching experience, and self-assessment regarding technological proficiency. Based on the broader literature concerning teacher use of technology, we expected that these factors would be related to teacher dashboard use. However, given the mixed findings in existing research, we do not pose any hypotheses for specific positive or negative relationships between the predicting variables and teacher dashboard use.

\section{Case Study A: Awareness and Interpretation Phase}

\subsection{Method}

\subsubsection{Context and Design}

The first case study was conducted in the context of computer-supported student collaboration on mathematics tasks. For collaboration between students to be successful, adequate teacher support is necessary (Gillies, Ashman, \& Terwel, 2008). As a first step, teachers need to be able to interpret which groups are in need of support. In the present case study, we examined whether mirroring and advising dashboards supported teachers in their interpretation of which groups need support, and whether teacher characteristics play a role in this process. We conducted an experiment in which student teachers were asked to interact with fictitious situations of collaborating students displayed on either a mirroring or an advising dashboard (see Figure 1).

\subsubsection{Participants}

The sample consisted of 35 participants, who were either pre-service primary school teachers or primary school teachers who had recently finished their teacher education. Teachers signed up for the experiment voluntarily and received monetary compensation for their participation. They were randomly distributed over the two conditions, leading to 17 in the mirroring condition (one male) and 18 in the advising condition (two males). Their mean age was $21.4(S D=2.2)$; on average they had 2.53 years teaching experience in primary education $(S D=1.28)$. Ten participants had experience with dashboards in their practice (5 in each condition). All participants had experience with teaching fractions and with collaborative activities in their classroom. No significant differences between the conditions were found regarding age and teaching experience $(p>.60$ in both cases). Since the sample only contained three male teachers, gender was not taken into account in further analyses.

\subsubsection{Instruments: Adaptive Learning Technology and Teacher Dashboard}

Teachers were told that their task was to imagine that they were teaching a 4th grade class, in which dyads of students were collaborating on the skills of naming fractions, simplifying fractions, and adding and subtracting fractions. Thus, teachers interacted with dashboards showing data from fictitious students. The eight situations were derived from the existing software MathTutor (2018), a program designed to practise mathematics (including fractions) in both individual and collaborative 
settings. With MathTutor, both students have their own computer screen, but the interface they control is the same. Each action on the interface is visible to the other dyad member, and by being seated next to each other and talking aloud, the dyad can discuss the assignments. Because MathTutor logs all student activity, these log-files can be processed and used as input for teacher dashboards. Two dashboard versions were compared in this study (see Figure 1). The dashboards were designed based on a literature review and a co-design phase with teachers taking the specific context into account (see Van Leeuwen et al., 2019).

The mirroring dashboard (Figure 1, top) provided information to the teacher about the collaborating dyads. The advising dashboard (Figure 1, bottom) additionally alerted the teachers about deviating groups and showed a short text about the dyads' situation.

Mirroring
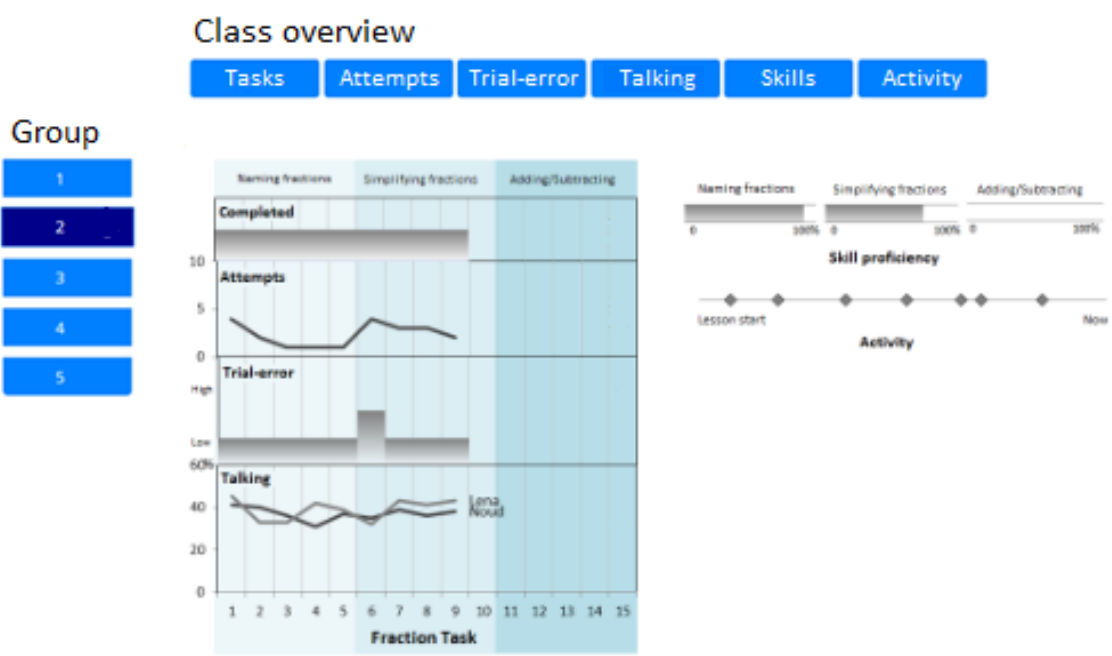

Advising

Class overview

\begin{tabular}{l|l|l|l|l|l|l|}
\hline Tasks & Attempts & Trial-error & Talking & Skills & Activity \\
\hline
\end{tabular}

Alert is

given for

group 2
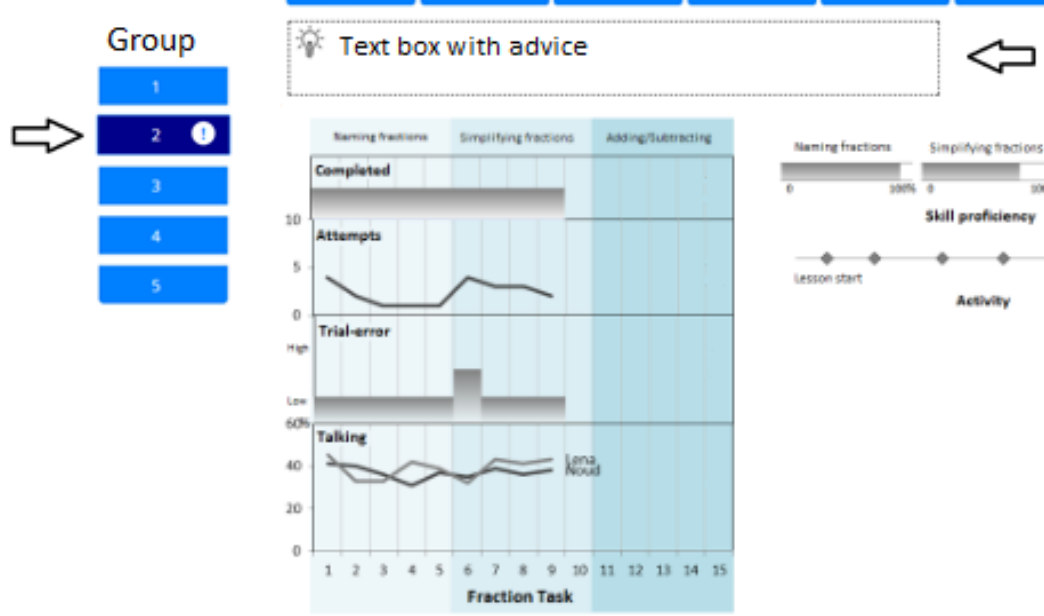

Short text

is shown

about

group 2

Figure 1. Screenshots of mirroring and advising teacher dashboards.

Teachers examined eight situations, each of which contained information about five collaborating dyads in the context of fraction assignments. Teachers could consult class overviews and request information about each individual group concerning six indicators: 1) number of tasks completed, 2) number of attempts per task, 3) chance of trial-and-error behaviour, 4) amount of talk within the dyad, 5) proficiency at three fraction skills, and 6) overall number of activities within the learning environment. Figure 2 shows an example of a group overview that displays these six indicators. 
Overview Group 1 - Lena and Noud
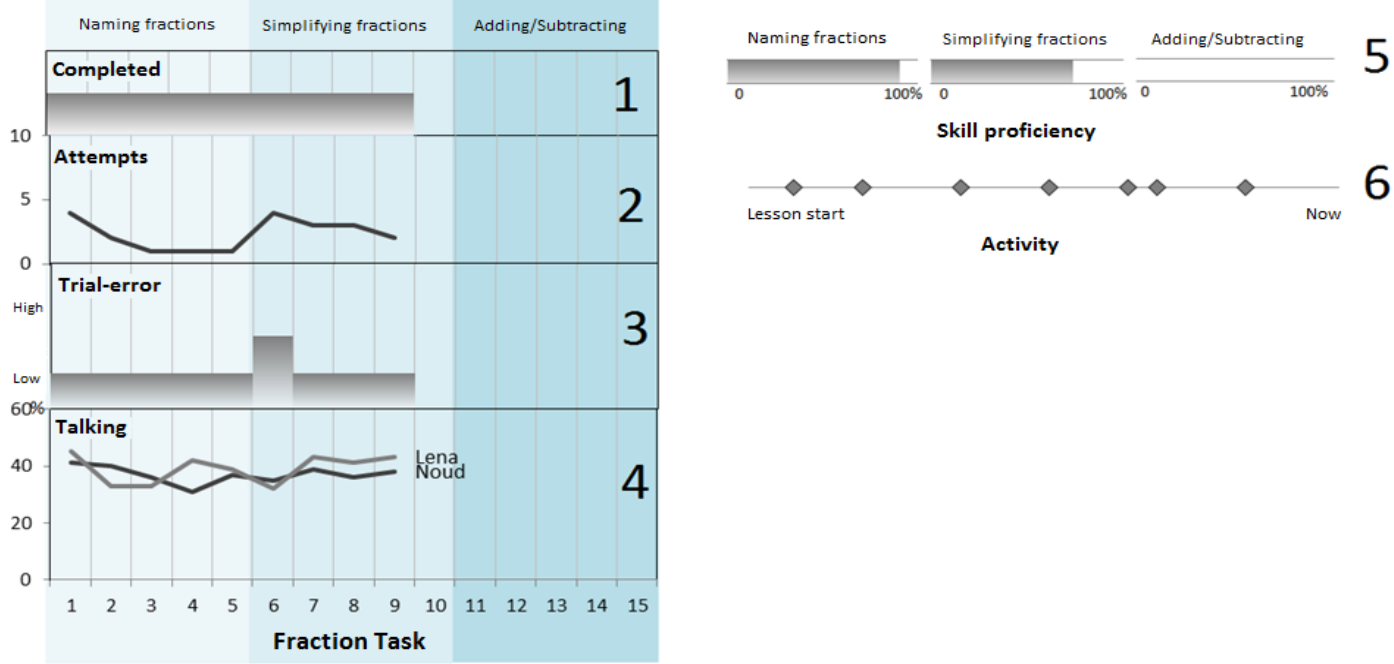

Figure 2. Screenshot of a group overview with 6 indicators.

\subsubsection{Instruments: Awareness and Interpretation}

The situations presented to the teachers contained one group of students who displayed problematic behaviour; for example, a group that made no progress on the fraction tasks. While interacting with the situations, all teachers' mouse clicks were captured in log-files. To measure teacher awareness of the dashboard, we calculated the average number of clicks per situation, as well as the clicks on group overview pages and indicator pages (class overviews). The clickstream data thus represented teacher requests for and awareness of information in terms of group level and class level. Teachers could press a button once they were finished looking at a situation. To simulate the time pressure that teachers have within classrooms, the situations ended automatically after 50 seconds. To measure teacher interpretation of the dashboard, at the end of each situation, teachers indicated which group they thought needed support. The sum of correctly identified groups $(\max =8)$ was used as a measure of teacher interpretation.

\subsubsection{Instruments: Teacher Characteristics}

At the start of the experiment, teachers filled in their amount of teaching experience (in months), and a 7-item questionnaire on their technological self-efficacy (on a scale from 1 to 5; $\alpha=0.88$; see Admiraal et al., 2017). The two conditions did not significantly differ concerning these variables. For the whole sample, an average of 30.4 months of teaching experience was reported $(S D=15.3)$, and teachers reported 4.0 on average on the technological self-efficacy scale $(S D=0.65)$.

\subsubsection{Data Analyses}

Since this dataset consisted of two conditions, we also had to account for the effect of those conditions. A hierarchical regression was performed, so that we could specify which predictors to enter to predict awareness and interpretation of dashboards. In the first model, only the experimental condition (as dummy variable) was entered. In the second model, the predictors of age, teaching experience, and technological self-efficacy were entered. This was done for each dependent variable. Since the sample only contained three male teachers, the role of gender was not investigated further.

\subsection{Results}

\subsubsection{Descriptives for Awareness and Interpretation}

Table 1 shows descriptive statistics for how often teachers, on average, consulted the available information per situation, and also shows how often, on average, they clicked on either group or class overview. It also shows how often they correctly interpreted which group was in need of support.

Table 1. Descriptive Statistics

\begin{tabular}{llllll}
\hline & \multicolumn{2}{l}{ Mirroring } & & \multicolumn{2}{l}{ Advising } \\
\cline { 3 - 4 } \cline { 5 - 7 } & $\mathrm{M}$ & $\mathrm{SD}$ & & $\mathrm{M}$ & $\mathrm{SD}$ \\
\hline Total clicks per situation & 9.9 & 2.5 & & 8.8 & 2.9 \\
Clicks on group overview & 2.5 & 2.3 & & 4.8 & 3.1 \\
Clicks on class overview & 7.4 & 1.4 & & 4.0 & 2.6 \\
Number of correct interpretations (out of 8) & 6.5 & 1.0 & & 7.2 & 0.7 \\
\hline
\end{tabular}




\subsubsection{The Role of Teacher Characteristics}

For the total number of clicks on the dashboard, no significant influence was found for either of the predictors. Thus, there was no influence of the type of dashboard, nor of any of the included teacher characteristics. When we zoom in on the clicks on the group pages specifically, we do find that the type of dashboard that teachers interacted with was a significant predictor, explaining $16.9 \%$ of variation. Teacher characteristics were no significant predictors of number of clicks on group pages (p values all above .3). For clicks on the indicator pages, we find the same pattern. The type of dashboard results in significant differences concerning the number of clicks (explaining $38.6 \%$ of variation), but the included teacher characteristics do not play a significant role ( $\mathrm{p}$ values all above .6).

Concerning interpretation, as expected, the experimental condition (i.e., type of dashboard) had a significant impact on detection of groups, explaining $11.5 \%$ of variation. Adding the predictors of age, teaching experience, and technological selfefficacy only slightly increased the explained variation to $14.2 \%$. When looking at the model's parameters, we found that age, teaching experience, and technological self-efficacy were no significant predictors for detection of groups (with $\mathrm{p}$ values of $.374, .386$, and .642 respectively).

Together, the results seem to suggest that it was the type of dashboard and the information that teachers selected on the dashboard that influenced their ability to detect the groups in need of support, and that the teacher characteristics we included did not play a role.

\section{Case Study B: Awareness and Enactment Phase}

\subsection{Method}

\subsubsection{Context and Design}

This observational study was conducted in classrooms that used an Adaptive Learning Technology (ALT) for mathematics on a daily basis. This technology provided teachers with dashboards that were concurrently updated during the lessons. During the lessons, teachers were observed by colleagues acting as coaches who were experts in working with the ALT and trained to observe teachers. We examined whether and how teacher gender, age, teaching experience, ALT experience, and self-reported and coach-reported ALT proficiency were associated with the enactment phase in terms of feedback that teachers provided to students, prompted by consulting the dashboard.

In total, 45 teachers were observed during one arithmetic lesson (50 minutes) taught using grade 2 (8-year-old students) to grade 6 (12-year-old students) regular school curriculum. Adaptive learning technology (ALT) was used in these classrooms on a daily basis. While students worked on solving problems in the ALT, real-time data was shown on the teacher dashboards. We observed how the teachers used the dashboard, and examined its relation to teacher characteristics.

\subsubsection{Participants}

In total, 45 teachers participated. As is true for other innovations in education, these teachers were expected to use the dashboard in their classroom based on a school-wide adoption of the adaptive learning technology. The teachers were mostly female (76\%), between 20 and 65 years old with equal representation of all ages and the corresponding range of teaching experience between two and 30 years. Teachers had between one and three years of experience in working with the ALT. Both teachers as well as their coaches indicated ALT proficiency as beginner, intermediate, or experienced (for exact numbers see Table 3, first column).

\subsubsection{Instruments: Adaptive Learning Technology and Teacher Dashboard}

The ALT used in this study, Snappet, runs on tablet computers and is widely used for arithmetic and spelling across schools in the Netherlands. The arithmetic problems in the ALT were comparable to those done by students in regular classrooms. The ALT offers both adaptive and non-adaptive problems. Non-adaptive problems were pre-selected for a particular topic and all students in the class received the same ones. The adaptive problems adjusted to the needs of the individual student based on a derivative of the Elo algorithm (Elo, 1978). The algorithm works with a student's knowledge score, which represents a student's current level of knowledge on a particular topic. This knowledge score is calculated based on all the problems that a student has worked on. Based on the student's knowledge level and the difficulty level of the problems, the ALT selects the next practice problem.

Teachers could view a visualization of student data on the corresponding dashboards (see Figure 3 ). The software captures real-time data on learner performance, immediately displayed to the teachers on dashboards. The dashboard was developed in a co-design process with primary school teachers and is updated in co-design efforts on a regular basis (Molenaar \& Knoopvan Campen, 2019). The first dashboard showed information about the problems students worked on. For every student, it indicated how many problems were solved (progress) and whether a problem was correctly answered (performance). The first section of the dashboard dealt with non-adaptive problems that were part of the lesson; the second section indicated adaptive problems a student is working on at an individual level. Finally, the progress indicator (the small figures in front of the student 
names in Figure 3) showed which students were making progress, not making progress, or unknown. The system defined these aspects based on an algorithm and visualized it with colour coding and symbols. The second dashboard presents more information at the individual student level. On the left are progress indicators on topics recently worked on. Different colours indicate mastery levels. The middle shows predictive analytics in the domain of arithmetic; on the right is an overview of topics mastered and those still needing attention. Teachers accessed the dashboards on their computer screen, laptop, or tablet. Computers and laptops were situated to be accessible for the teacher during lessons.
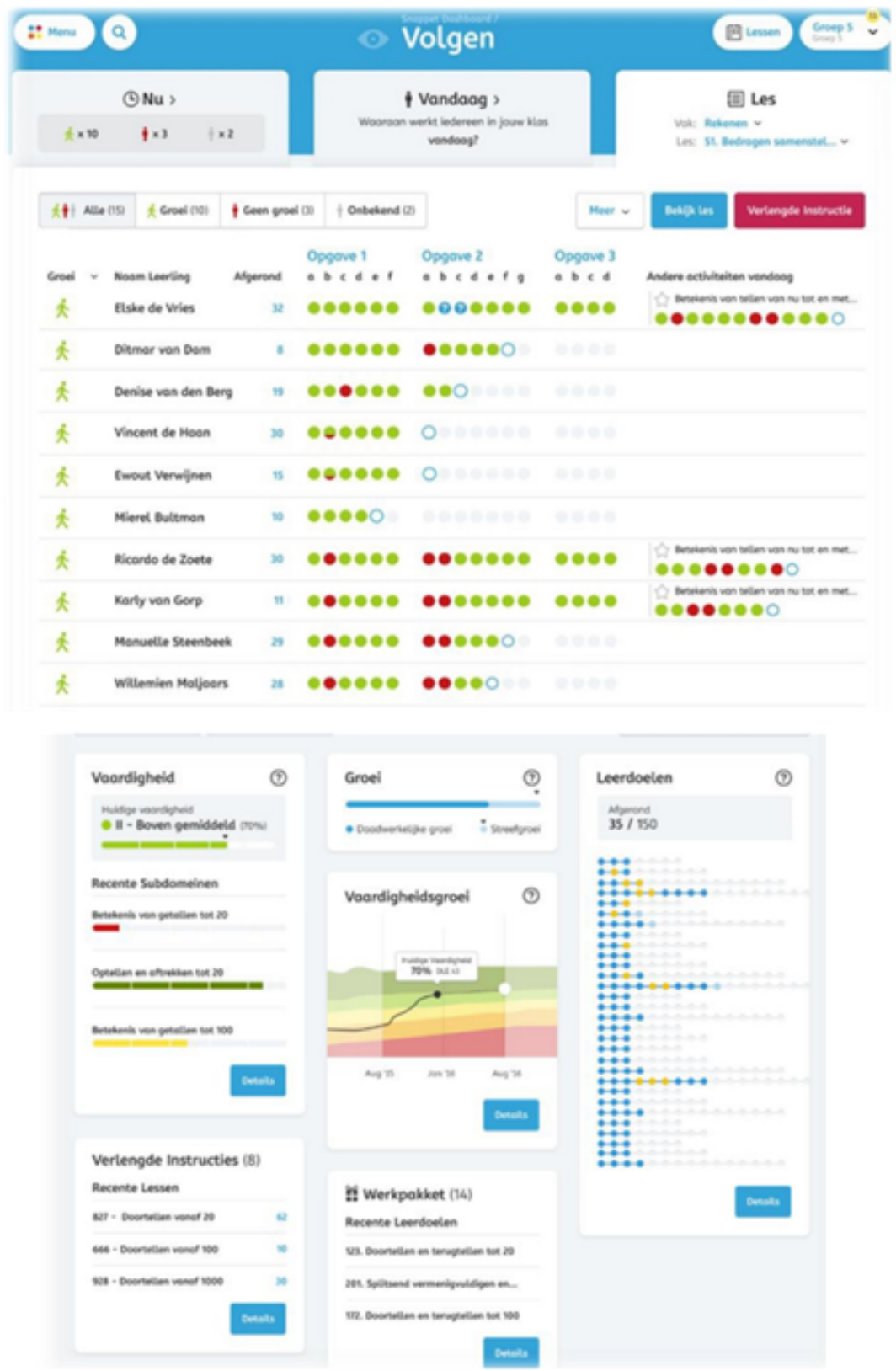

Completed exercises per student. Green indicates successfully completed exercises.
Information about students' acquired skills and learning goals.

Figure 3. The teacher dashboards.

\subsubsection{Instruments: Awareness and Enactment}

Observations of teacher use of the dashboard and the enactment phase were performed by coaches (expert-teachers on the learning analytics with a coaching function) using the Classroom Observation App (Molenaar \& Knoop-van Campen, 2017b). The coaches were trained to observe how often teachers consulted the dashboard and to classify if feedback was given, and which type, after dashboard consultation. A distinction was made (see Table 2) between task, person, process, social, and metacognitive feedback (Keuvelaar-van den Bergh, 2013; Hattie \& Timperley, 2007; Molenaar \& Knoop-van Campen, 2019). Further information about patterns in feedback practices is reported in Knoop-van Campen and Molenaar (2020). 
Table 2. Types of Feedback

\begin{tabular}{|c|c|c|}
\hline $\begin{array}{l}\text { Type of } \\
\text { feedback }\end{array}$ & Explanation & Example \\
\hline Task & $\begin{array}{l}\text { The teacher comments on how well assignments } \\
\text { are understood/performed. Feedback on the } \\
\text { content of the assignment. }\end{array}$ & $\begin{array}{l}\text { "You made a mistake because you forgot } \\
\text { to add these two numbers that you had to } \\
\text { keep in mind." }\end{array}$ \\
\hline Process & $\begin{array}{l}\text { The teacher provides feedback on the way children } \\
\text { handle their assignments. }\end{array}$ & $\begin{array}{l}\text { "Tim, please read the explanation before } \\
\text { you start working on your problems." }\end{array}$ \\
\hline Personal & The teacher comments on the student as a person. & "You are doing great!" \\
\hline Metacognition & $\begin{array}{l}\text { The teacher comments on the student schedule or } \\
\text { evaluation. }\end{array}$ & $\begin{array}{l}\text { "How are you going to check if you } \\
\text { solved this correctly?" }\end{array}$ \\
\hline Social & $\begin{array}{l}\text { The teacher comments on the co-operative } \\
\text { learning skills and social skills of students. }\end{array}$ & $\begin{array}{l}\text { "Please give positive feedback to group } \\
\text { members." }\end{array}$ \\
\hline
\end{tabular}

Awareness was defined as dashboard consultations (i.e., the number of times a teacher looked at the dashboard). Similar to study A, these data thus represented teacher requests for and awareness of information about the students. The enactment phase was studied in terms of the proportion of dashboard consultations leading to feedback actions, and the proportion of feedback by the teacher that was prompted by a dashboard consultation. For the dashboard-prompted feedback, it was coded 1) what type of feedback was given (task, process, personal, metacognitive, social) and 2) how many different types of feedback were given (feedback diversity).

\subsubsection{Instruments: Teacher Characteristics}

The teacher characteristics measured were gender, age, teaching experience, ALT experience, and self-reported and coachreported ALT proficiency. Each independent variable was divided into two, three, or four groups (depending on the nature of the variable) for group comparisons (see Table 3). Gender was dichotomous (male/female). Teachers were divided into four age groups (20-30 years, $30-40$ years, $40-50$ years, $50+$ years), three groups concerning teaching experience ( $0-10$ years, $10-$ 20 years, $20+$ years), and three groups concerning ALT experience (1 year, 2 years, $3+$ years). This grouping was based on earlier analyses reported in Molenaar and Knoop-van Campen (2017a; 2017b). Self-reported ALT proficiency was measured by asking teachers to indicate their level of experience with the ALT (beginner, intermediate, expert). Coach-reported ALT proficiency was indicated by the coaches who supported the teachers during the school year in working with the ALT (beginner, intermediate, expert).

\subsubsection{Data Analyses}

To examine how teacher characteristics (age, gender, teaching experience, ALT experience, self-reported ALT proficiency, coach-reported ALT proficiency) were related to the enactment phase, due to the small sample size non-parametric analyses were performed with the Independent-Samples Mann-Whitney test for gender and Kruskal-Wallis Tests for the other characteristics. The significance threshold was set to $p<.05$.

\subsection{Results}

\subsubsection{Descriptives for Awareness and Enactment}

Regarding dashboard consultations, teachers checked the dashboard on average 8.53 times $(S D=8.34)$ during a lesson. Eight teachers never consulted the dashboard. The proportion of feedback after dashboard consultation is $77 \%(S D=23 \%)$; teachers who consulted the dashboard $(n=37)$ provided feedback after $77 \%$ of the consultations. This corresponds to an average of $6.60(S D=6.87)$ feedback actions. The proportion of dashboard-prompted feedback (feedback after consultation) consisted of $13 \%$ of all feedback actions (the remaining $87 \%$ of feedback was given on the teacher's own initiative or in response to student questions).

The types of feedback given after dashboard consultation were, on average, 2.36 times task feedback $(S D=3.36,36 \%)$, 1.80 times process feedback $(S D=2.63,27 \%), 1.80$ times personal feedback $(S D=2.79,27 \%), .58$ times metacognitive feedback $(S D=1.52,9 \%)$, and .07 times social feedback $(S D=.32,1 \%)$. Regarding dashboard-prompted feedback diversity, on average teachers used $2.24(S D=.98)$ different types of feedback after dashboard consultation.

\subsubsection{The Role of Teacher Characteristics}

Regarding the association between teacher characteristics and the awareness and enactment phases (see Table 3), we found that none of the predictors (dashboard consultations, proportion feedback after dashboard consultation, proportion dashboardprompted feedback, type of dashboard-prompted feedback, and dashboard-prompted feedback diversity) were associated with gender, age, teaching experience, ALT experience or self-reported ALT proficiency ( $p$ 's $>.05)$. 
Table 3. Dashboard Use and Dashboard-Prompted Feedback per Teacher Characteristics in Study B

\begin{tabular}{|c|c|c|c|c|c|c|c|c|c|c|c|}
\hline & & $\mathrm{N}$ & $\begin{array}{l}\text { Dashboard } \\
\text { consultations }\end{array}$ & $\begin{array}{l}\text { Proportion of } \\
\text { feedback } \\
\text { after } \\
\text { dashboard } \\
\text { consultation } \\
\text { M (SD) } \\
\end{array}$ & $\begin{array}{c}\text { Proportion of } \\
\text { dashboard- } \\
\text { prompted } \\
\text { feedback } \\
\text { M (SD) }\end{array}$ & $\begin{array}{c}\text { Task } \\
\text { feedback }\end{array}$ & $\begin{array}{l}\text { Process } \\
\text { feedback }\end{array}$ & $\begin{array}{l}\text { Personal } \\
\text { feedback }\end{array}$ & $\begin{array}{l}\text { Meta- } \\
\text { cognitive } \\
\text { feedback } \\
\text { M (SD) }\end{array}$ & $\begin{array}{c}\text { Social } \\
\text { feedback }\end{array}$ & $\begin{array}{c}\text { Dashboard- } \\
\text { prompted } \\
\text { feedback } \\
\text { diversity } \\
\text { M (SD) }\end{array}$ \\
\hline \multirow[t]{3}{*}{ Gender } & & 45 & $8.53(8.34)$ & $77.12(23.05)$ & $12.54(11.64)$ & $2.36(3.36)$ & $1.62(2.37)$ & $1.80(2.79)$ & $.58(1.63)$ & $.07(.33)$ & $2.25(.97)$ \\
\hline & Male & 11 & $9.45(7.78)$ & $79.77(21.48)$ & $16.37(15.43)$ & $2.91(3.02)$ & $2.36(3.38)$ & $2.00(3.49)$ & $.27(.65)$ & $.18(.60)$ & $2.22(1.09)$ \\
\hline & Female & 34 & $8.24(8.60)$ & $76.27(23.85)$ & $11.30(10.10)$ & $2.18(3.49)$ & $1.80(2.63)$ & $1.74(2.59)$ & $.68(1.84)$ & $.03(.17)$ & $2.24(.98)$ \\
\hline \multirow[t]{5}{*}{ Age } & & 39 & $8.49(8.20)$ & $76.10(23.57)$ & $12.75(11.63)$ & $2.51(3.53)$ & $1.69(2.42)$ & $1.72(2.61)$ & $.41(1.07)$ & $.08(.35)$ & $2.15(.93)$ \\
\hline & $20-30$ years & 10 & $6.40(4.86)$ & $66.70(30.65)$ & $9.63(7.15)$ & $2.10(3.32)$ & $1.30(2.21)$ & $.70(1.25)$ & $.20(.63)$ & $.10(.32)$ & $1.56(.73)$ \\
\hline & $30-40$ years & 8 & $7.88(5.79)$ & $70.48(22.72)$ & $13.38(9.19)$ & $1.63(1.69)$ & $1.63(2.26)$ & $1.13(1.46)$ & $.75(1.75)$ & .00 (na) & $2.14(.90)$ \\
\hline & $40-50$ years & 12 & $9.58(10.21)$ & $77.04(21.85)$ & $12.28(11.23)$ & $2.50(2.91)$ & $2.25(3.33)$ & $2.08(2.64)$ & $.58(1.17)$ & $.00(\mathrm{na})$ & $2.50(.97)$ \\
\hline & $50+$ years & 9 & $9.89(10.51)$ & $90.42(10.39)$ & $16.29(17.61)$ & $3.78(5.47)$ & $1.44(1.33)$ & $2.89(3.95)$ & $.11(.33)$ & $.22(.67)$ & $2.38(.92)$ \\
\hline \multicolumn{2}{|c|}{ Teaching experience } & 39 & $8.49(8.20)$ & $76.10(23.57)$ & $12.75(11.63)$ & $2.51(3.53)$ & $1.69(2.42)$ & $1.72(2.61)$ & $.41(1.07)$ & $.08(.35)$ & $2.15(.93)$ \\
\hline & $0-10$ years & 14 & $6.43(5.36)$ & $67.84(26.64)$ & $8.91(6.63)$ & $2.14(2.93)$ & $1.29(1.90)$ & $.64(1.15)$ & $.21(.58)$ & $.07(.27)$ & $1.83(.94)$ \\
\hline & $20+$ years & 11 & $10.73(10.33)$ & $78.47(18.01)$ & $13.92(16.22)$ & $4.00(5.20)$ & $1.36(1.50)$ & $2.64(3.80)$ & $.18(.41)$ & $.18(.60)$ & $2.44(.73)$ \\
\hline \multirow[t]{4}{*}{ ALT experience } & & 39 & $8.49(8.20)$ & $76.10(23.57)$ & $12.75(11.63)$ & $2.51(3.53)$ & $1.69(2.42)$ & $1.72(2.61)$ & $.41(1.07)$ & $.08(.35)$ & $2.15(.93)$ \\
\hline & 1 year & 11 & $8.45(8.78)$ & $73.99(26.40)$ & $9.05(7.85)$ & $2.36(5.10)$ & $1.27(1.49)$ & $2.18(2.44)$ & $.36(.67$ & $.00(\mathrm{na})$ & $2.22(.44)$ \\
\hline & 2 years & 14 & $9.86(9.42)$ & $80.30(22.39)$ & $15.88(10.80)$ & $3.00(2.75)$ & $2.79(3.47)$ & $1.36(2.53)$ & $.71(1.64)$ & $.00(\mathrm{na})$ & $2.08(1.04)$ \\
\hline & $3+$ years & 14 & $7.14(6.68)$ & $73.13(24.06)$ & $12.53(14.45)$ & $2.14(2.91)$ & $.93(1.14)$ & $1.71(2.92)$ & $.14(.36)$ & $.21(.58)$ & $2.17(1.12)$ \\
\hline \multicolumn{2}{|c|}{ Self-reported ALT proficiency } & 33 & $8.58(8.74)$ & $75.03(23.56)$ & $12.62(12.18)$ & $2.79(3.72)$ & $1.79(2.56)$ & $1.64(2.70)$ & $.27(.80)$ & $.06(.35)$ & $2.14(.97)$ \\
\hline & Beginner & 5 & $3.00(2.35)$ & $65.00(41.23)$ & $4.02(3.30)$ & $.20(.45)$ & $.80(.84)$ & $.40(.89)$ & $.20(.45)$ & .00 (na) & $1.50(.58)$ \\
\hline & Intermediate & 13 & $10.77(11.51)$ & $76.94(21.10)$ & $14.38(15.21)$ & $3.23(4.57)$ & $2.31(3.45)$ & $2.46(3.80)$ & $.38(1.12)$ & $.15(.56)$ & $2.36(1.12)$ \\
\hline & Experienced & 15 & $8.53(6.62)$ & $76.50(19.54)$ & $13.96(10.31)$ & $3.27(3.31)$ & $1.67(1.99)$ & $1.33(1.68)$ & $.20(.56)$ & $.00(\mathrm{na})$ & $2.15(.90)$ \\
\hline \multirow[t]{3}{*}{ Coach-reported Al } & LT proficiency & 43 & $8.30(8.45)$ & $78.80(22.55)$ & $12.70(11.87)$ & $2.47(3.40)$ & $1.77(2.67)$ & $1.72(2.83)$ & $.60(1.66)$ & $.05(.31)$ & $2.23(1.00)$ \\
\hline & Beginner & 11 & $5.36(7.19)$ & $74.26(32.13)$ & $6.64(8.77)$ & $.73(1.79)$ & $1.36(2.11)$ & $1.18(2.99)$ & $\begin{array}{l}1.00 \\
(2.68)\end{array}$ & $.00(\mathrm{na})$ & $2.14(1.07)$ \\
\hline & Intermediate & 17 & $8.12(8.15)$ & 83.61 (19.74) & $11.85(9.01)$ & $2.71(4.14)$ & $1.65(2.57)$ & $1.53(2.24)$ & $.65(1.27)$ & $.00(\mathrm{na})$ & $2.21(1.06)$ \\
\hline
\end{tabular}


We did find that the coach-reported ALT proficiency was related to the proportion of dashboard-prompted feedback; teachers judged as experienced gave relatively more dashboard-prompted feedback $(M=18.10 \%, S D=14.63)$ compared to teachers judged as beginners $(M=6.64 \%, S D=8.77)$. Hence these teachers had a large proportion of dashboard-prompted feedback in relation to human-prompted feedback practices. In addition, teachers judged as experienced gave more task feedback after dashboard consultations $(M=3.47, S D=3.04)$, compared to teachers judged as beginners $(M=.73, S D=1.79)$.

\section{Discussion}

In this paper, we examined the awareness, interpretation, and enactment phases of teacher use of dashboards, and their relation to teacher characteristics. Regarding case study A, the results showed that the function of the dashboard influenced teacher interpretation in terms of how well teachers detected the collaborating group in need of support. Surprisingly, neither amount of teaching experience nor technological self-efficacy significantly predicted their interpretation. With respect to case study $\mathrm{B}$, teacher age, gender, teaching experience, ALT experience, and self-reported ALT proficiency did not explain the variation in dashboard use in the enactment phase. Only coach-reported ALT proficiency was related to the enactment phase: Teachers judged as more proficient gave proportionally more dashboard-prompted feedback and more task feedback after dashboard consultations than teachers judged as less proficient.

\subsection{Discussion of Findings}

As expected, in both case studies we found large variation in teacher consultations of the dashboard and the subsequent use of the dashboard in terms of the awareness, interpretation, and enactment phases. These results are in line with previous literature (e.g., Herodotou et al., 2019; Molenaar \& Knoop-van Campen, 2019; Van Leeuwen et al., 2019) and highlight the need to further investigate how teachers interpret information on dashboards and translate dashboard information into action. In case study A, a finding similar to previous studies was the variation in the number of clicks on the dashboard and the type of information that teachers clicked on (Van Leeuwen et al., 2019). A high number of clicks on the dashboard could indicate that at least some teachers were mostly on the lookout for visual indicators of whether a group showed deviating behaviour by checking whether their graphs showed remarkable peaks or not. Concerning whether teachers correctly interpreted which group needed support, mixed findings have been reported in previous literature (Van Leeuwen et al., 2014; 2015). It must be noted that those previous studies compared a condition with learning analytics to a condition without learning analytics. The present case was different in the sense that different types of learning analytics dashboards were compared. In this study, we found less variation in dashboard interpretation within the two conditions compared to previous studies, with relatively small standard deviations within the mirroring and advising conditions.

Case study B replicated earlier findings indicating large variation in teacher consultation of dashboards (Molenaar \& Knoop-van Campen, 2017a; 2019). Again, the average number of dashboard consultations per lesson was eight and the variation between teachers was even larger ( $8 \%$ in the present study vs. $5 \%$ in previous studies; Molenaar \& Knoop-van Campen, 2017a). Three-quarters of dashboard consultations were followed by a feedback action, but this too differed greatly between teachers since the standard deviation was $26 \%$. We also observed a shift in the type of feedback following dashboard consultations compared to our previous study (Molenaar \& Knoop-van Campen, 2019); task feedback was now the most prevalent, process feedback was used slightly less, and the amount of personal feedback as well as metacognitive feedback in the lessons was greater. The variation in dashboard-prompted feedback diversity was again substantial and even slightly larger in the present study compared to the previous study (Molenaar \& Knoop-van Campen, 2017a).

In contrast to our expectations, teacher characteristics showed surprisingly little association with dashboard interpretation and enactment. Only coach-reported ALT proficiency (case study B) was related to the enactment phase. Coach-reported ALT proficiency was based on the observations of experienced teacher-coaches specialized in the use of ALT. This finding indicates an observable difference between teachers implementing the dashboards in their practice, especially between novice and expert teachers. Since previous research indicated that teacher characteristics such as age, gender, and technological skills played a role in teacher use of technology (Venkatesh et al., 2003), we hypothesized that they would also affect teacher use of dashboards.

Several explanations could be considered for why we did not find strong relationships between teacher characteristics and dashboard use. First, it is important to consider the features of the two case studies conducted, which differed considerably in some aspects. Study A was conducted with a methodology that controlled for very specific aspects of the situation that might act as confounding factors. Study B, on the other hand, was conducted in an actual classroom. However, the case studies also share important characteristics, which is what led us to include both of them in this paper. Both focus on dashboards aimed at real-time, in-class use by the teacher, constituting a very specific use-case. This commonality is also reflected by the results of both studies, which point in the same direction, adding to their validity. On the other hand, both case studies were relatively 
small in scale and unarguably, to some extent, under-powered, which means that the results must be interpreted with caution. A further limitation is that we did not include user perceptions that could be gained through interviews or focus groups to corroborate the quantitative findings. Future research could include this type of data to triangulate the quantitative and qualitative data, and thereby obtain further insight into the role of teacher characteristics. Our studies were first attempts to study the role of teacher characteristics in relation to dashboard use and should be seen as a starting point for further research. They therefore fit into recent developments in the field of LA to take a human-centred approach to the design and implementation of dashboards (Buckingham Shum et al., 2019).

A second explanation for our findings may be that the general teacher characteristics we studied were too simplistic to explain the complex phenomenon of teacher dashboard use. Even though these characteristics were based on existing literature and thus a logical first step in explaining the variation in teacher dashboard use, they were quite general (e.g., gender and years of experience). It could be that the use of dashboards in the classroom requires specific knowledge and skills different from those required for other technologies, such as a digital whiteboard or drill-and-practice software. More refined measurements of teacher knowledge and skills relevant for this specific context may turn out to be more successful in explaining this variation.

\subsection{Directions for Future Research}

Based on the discussion above, we hypothesize that in order to understand teacher dashboard use, an additional, more specific array of teacher characteristics needs to be considered. In Figure 4 we propose a first integrated model to guide future work and to develop our understanding of the relations between teacher characteristics and the variation in dashboard usage. The top layer of this model contains the three overarching phases that teachers must go through to use dashboards in educational contexts: awareness, interpretation, and enactment (Molenaar \& Knoop-van Campen, 2019; Van Leeuwen et al., 2019; Wise \& Jung, 2019). In the lowest part of the model, the more general teacher characteristics such as age and gender are included. Between these two layers, we propose including another layer of more specific teacher characteristics, more directly related to dashboard use. We hypothesize that general teacher characteristics relate to these more sophisticated characteristics, and only indirectly relate to dashboard use. This could explain why the relationships we examined were not significant.

Below, we highlight three teacher characteristics that could play a role in this middle layer. First, pedagogical knowledge a combination of knowledge about pedagogy, content, and learner characteristics - supports teachers in selecting effective pedagogical actions (Gudmundsdottir \& Shulman, 1987). Pedagogical knowledge forms the basis for a teacher's repertoire of pedagogical actions and therefore can support the enactment phase in which teachers select appropriate actions. In the context of collaborative learning, this also includes knowledge of effective student actions and trajectories during collaborative learning (case study A). Content knowledge relates to domain-specific knowledge that improves teaching in a particular domain. This content knowledge helps give meaning to dashboard information, for example, by helping teachers to understand the types of mistakes students make. Finally, knowledge about learner characteristics helps teachers understand learner behaviours and can help to determine appropriated pedagogical actions. This knowledge interacts with teacher perceptions of students that also play a role in teachers' pedagogical practices (Kaiser, Südkamp, \& Möller, 2017) and consequently can be expected to affect how teachers enact dashboard information. For example, when teacher perceptions about their students and their observations on the dashboards are misaligned, this may affect how teachers value the dashboard information. Next to the regular components of teachers' pedagogical knowledge base, their analytics skills are a new component that is potentially important to explain variation in teacher dashboard usage.

Second, we propose to study teachers' professional routines, which are patterns and routines of actions, interaction, and sense-making that teachers enact in the classroom (Ballet \& Kelchermans, 2009). These routines are based on the complex integration of teacher perceptions, pedagogical and content knowledge, and skills in their pedagogical knowledge base (Roelofs \& Sanders, 2007; Verloop, Van Driel, \& Meijer, 2001). Through professional routines, teachers' pedagogical knowledge is applied within the contexts of the classroom. An example of a study that highlights the importance of teacher routines for dashboard usage specifies two groups of teachers, a group that uses the dashboards in one sequence and a group that alternates between the dashboard, providing feedback on their own initiative, and answering student questions (Knoop-van Campen \& Molenaar, 2020). It was demonstrated that the teacher routine for using the dashboard predicted the type of feedback that teachers gave. Teachers who alternated between the dashboard and other sources of feedback gave more process feedback, whereas teachers who used dashboards in blocks provided mostly personal feedback. We note that professional routines are difficult to measure, but proxies of routines, like the temporal order in dashboard-prompted feedback, offer a possible way to move forward.

Third, teachers' ability to transform information into actionable instructional knowledge and practices, also known as data literacy (Mandinach \& Gummer, 2016), could play a role in teacher dashboard use. This ability can be seen as a combination of being able to read and interpret information, and possessing the skill to connect those inferences to relevant pedagogical knowledge to select an adequate follow-up action. Data literacy is therefore a quite complicated construct (Mandinach \& Gummer, 2016), which also implicates that measurement of this construct may encompass measuring several aspects, such as 
graph literacy (Van Den Bosch, Espin, Chung, \& Saab, 2017) or the previously mentioned pedagogical knowledge. Although the importance of data literacy is acknowledged, Schwendimann and colleagues (2017) indicate in their review of dashboards in the context of education that there is very little research that explores the relation between users' data literacy and the usefulness of a dashboard. Studying the role of data literacy in more detail could therefore be an avenue for further research.

If one of these specific teacher characteristics indeed turns out to be predictive of dashboard use, practical recommendations could be provided aimed at professional development in these areas. For example, professional routines can be adapted and improved by peer observations and guided reflection (Roelofs \& Sanders, 2007). Interventions aimed at stimulating data literacy, for example, include training programs that allow teachers to practise the complexities of connecting observations gained from data to decisions about pedagogical actions (Mandinach \& Gummer, 2016). Of course, it is important that future research first establish the extent to which these characteristics play a role in dashboard use before recommending detailed practical application of the findings.

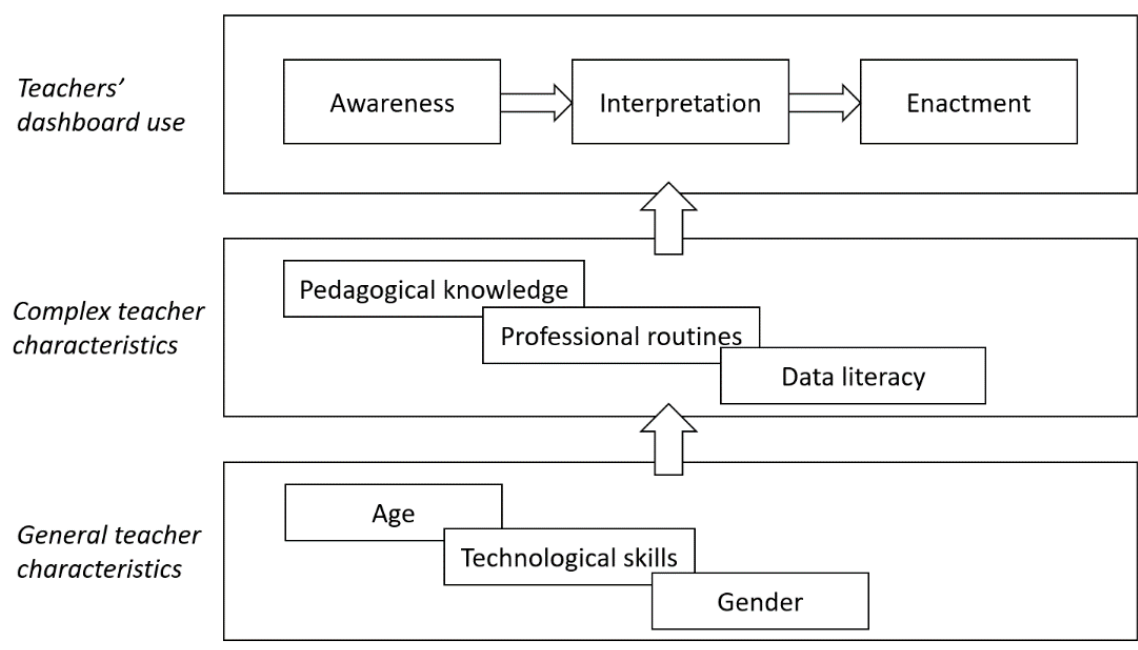

Figure 4. Proposal for an integrated model of teacher dashboard usage.

\subsection{Conclusion}

The present paper was a first attempt in explaining variations in teacher dashboard use based on teacher characteristics. The characteristics used were chosen based on previous literature and provided a reasonable starting point for our inquiry. From our two case studies, it was shown that general teacher characteristics did not explain the variation in teacher dashboard use in the awareness, interpretation, and enactment phases. Even though these results should be interpreted cautiously, the positive news is that professional routines regarding dashboard use do not seem to be dependent on particular teacher characteristics. These initial findings are encouraging since they indicate that no extensive experience or technological skills seem necessary for using teacher dashboards. Hence all teachers may develop these routines. The drawback is that professional development programs cannot be tailored based simply on teacher characteristics or their own judgment of their practices. This paper should therefore be seen as a first step in examining the role of teacher characteristics in dashboard use in education. To move the field further, we proposed an integrated model to help understand teacher dashboard use and to guide future research.

\section{Declaration of Conflicting Interest}

The authors declared no potential conflicts of interest with respect to the research, authorship, and/or publication of this article.

\section{Funding}

Study A was funded by the Netherlands Organization for Scientific Research (NWO) through a Rubicon grant (\#446-16003/1276). Study B was funded by NRO (\#405-15-823) as part of the national research program "Breakthrough Project Technology in Education" (doorbraakproject onderwijs \& ICT).

\section{References}

Admiraal, W., Louws, M., Lockhorst, D., Paas, T., Buynsters, M., Cviko, A., ... \& Kester, L. (2017). Teachers in schoolbased technology innovations: A typology of their beliefs on teaching and technology. Computers and Education, 114, 57-68. https://doi.org/10.1016/j.compedu.2017.06.013 
Aleven, V., McLaughlin, E. A., Glenn, R. A., \& Koedinger, K. R. (2016). Instruction based on adaptive learning technologies. In R. E. Mayer \& P. Alexander (Eds.), Handbook of research on learning and instruction. Abingdon-onThames, UK: Routledge.

Ballet, K., \& Kelchtermans, G. (2009). Struggling with workload: Primary teachers' experience of intensification. Teaching and Teacher Education, 25(8), 1150-1157. https://doi.org/10.1016/j.tate.2009.02.012

Buckingham Shum, S., Ferguson, R., \& Martinez-Maldonado, R. (2019). Human-centred learning analytics. Journal of Learning Analytics, 6(2), 1-9. https://doi.org/10.18608/jla.2019.62.1

Butler, D. L., \& Winne, P. H. (1995). Feedback and self-regulated learning: A theoretical synthesis. Review of Educational Research, 65(3), 245-281. https://doi.org/10.3102/00346543065003245

de Jager, B., Jansen, M., \& Reezigt, G. (2005). The development of metacognition in primary school learning environments. School Effectiveness and School Improvement, 16(2), 179-196. https://doi.org/10.1080/09243450500114181

Elo, A. (1978). The rating of chess players, past and present. New York: Arco.

Gillies, R. M., Ashman, A., \& Terwel, J. (Eds.) (2008). The teacher's role in implementing cooperative learning in the classroom. New York: Springer. https://doi.org/10.1007/978-0-387-70892-8

Gudmundsdottir, S., \& Shulman, L. (1987). Pedagogical content knowledge in social studies. Scandinavian Journal of Educational Research, 31(2), 59-70. https://doi.org/10.1080/0031383870310201

Hattie, J. (2012). Visible learning for teachers: Maximizing impact on learning. Abingdon-on-Thames, UK: Routledge.

Hattie, J., \& Timperley, H. (2007). The power of feedback. Review of Educational Research, 77(1), 81-112. https://doi.org/10.3102/003465430298487

Herodotou, C., Rienties, B., Boroowa, A., Zdrahal, Z., \& Hlosta, M. (2019). A large-scale implementation of predictive learning analytics in higher education: The teachers' role and perspective. Educational Technology Research and Development, 67(5), 1273-1306. https://doi.org/10.1007/s11423-019-09685-0

Hutchins, E. (2000). Distributed cognition. In International encyclopedia of the social and behavioral sciences. Amsterdam, Netherlands: Elsevier Science.

Kaiser, J., Südkamp, A., \& Möller, J. (2017). The effects of student characteristics on teachers' judgment accuracy: Disentangling ethnicity, minority status, and achievement. Journal of Educational Psychology, 109(6), 871-888. https://doi.org/10.1037/edu0000156

Keuvelaar-van den Bergh, L. (2013). Teacher feedback during active learning: The development and evaluation of a professional development programme. https://surfsharekit.nl/publiek/fontys/9d02c698-55da-43c2-8390-99483f29e010

Knoop-van Campen, C. A. N, \& Molenaar, I. (2020). How teachers integrate dashboards into their feedback practices. Frontline Learning Research, 8(4), 37-51. http://doi.org/10.14786/flr.v8i4.641

Lin, T.-C., Tsai, C.-C., Chai, C. S., \& Lee, M.-H. (2013). Identifying science teachers' perceptions of technological pedagogical and content knowledge (TPACK). Journal of Science Education and Technology, 22(3), 325-336. https://doi.org/10.1007/s10956-012-9396-6

Mandinach, E. B., \& Gummer, E. S. (2016). What does it mean for teachers to be data literate: Laying out the skills, knowledge, and dispositions. Teaching and Teacher Education, 60, 366-376.

https://doi.org/10.1016/j.tate.2016.07.011

MathTutor (2018). https://mathtutor.web.cmu.edu/

Martinez-Maldonado, R., Clayphan, A., Yacef, K., \& Kay, J. (2014). MTFeedback: Providing notifications to enhance teacher awareness of small group work in the classroom. IEEE Transactions on Learning Technologies, 8(2), 187200. https://doi.org/10.1109/TLT.2014.2365027

Melero, J., Hernández-Leo, D., Sun, J., Santos, P., \& Blat, J. (2015). How was the activity? A visualization support for a case of location-based learning design. British Journal of Educational Technology, 46(2), 317-329.

https://doi.org/10.1111/bjet.12238

Molenaar, I., \& Knoop-van Campen, C. A. N. (2017a). Teacher dashboards in practice: Usage and impact. Proceedings of the $12^{\text {th }}$ European Conference on Technology Enhanced Learning (EC-TEL 2017), 12-15 September 2017, Tallinn, Estonia (pp. 125-138). Lecture Notes in Computer Science. Springer, Cham. https://doi.org/10.1007/978-3-319$\underline{66610-5 \quad 10}$

Molenaar, I., \& Knoop-van Campen, C. A. N. (2017b). How teachers differ in using dashboards: The classroom observation app. Paper presented at the Multimodal Learning Analytics Across (Physical and Digital) Spaces workshop at the $12^{\text {th }}$ European Conference on Technology Enhanced Learning (EC-TEL 2017), 12-15 September 2017, Tallinn, Estonia.

Molenaar, I., \& Knoop-van Campen, C. (2019). How teachers make dashboard information actionable. IEEE Transactions on Learning Technologies 12(3), 347-355. https://doi.org/10.1109/TLT.2018.2851585 
Mueller, J., Wood, E., Willoughby, T., Ross, C., \& Specht, J. (2008). Identifying discriminating variables between teachers who fully integrate computers and teachers with limited integration. Computers and Education, 51(4), 1523-1537. https://doi.org/10.1016/j.compedu.2008.02.003

Rienties, B., Herodotou, C., Olney, T., Schencks, M., \& Boroowa, A. (2018). Making sense of learning analytics dashboards: A technology acceptance perspective of 95 teachers. International Review of Research in Open and Distributed Learning, 19(5). https://doi.org/10.19173/irrodl.v19i5.3493

Roelofs, E., \& Sanders, P. (2007). Towards a framework for assessing teacher competence. European Journal of Vocational Training, 40(1), 123-139. https://files.eric.ed.gov/fulltext/EJ776614.pdf

Schwarz, B. B., \& Asterhan, C. S. (2011). E-moderation of synchronous discussions in educational settings: A nascent practice. Journal of the Learning Sciences, 20(3), 395-442. https://doi.org/10.1080/10508406.2011.553257

Schwendimann, B., Rodriguez-Triana, M., Vozniuk, A., Prieto, L., Boroujeni, M., Holzer, A., ... Dillenbourg, P. (2017). Perceiving learning at a glance: A systematic literature review of learning dashboard research. IEEE Transactions on Learning Technologies, 10(1), 30-41. https://doi.org/10.1109/TLT.2016.2599522

Sergis, S., \& Sampson, D. G. (2017). Teaching and learning analytics to support teacher inquiry: A systematic literature review. In A. Peña-Ayala (Ed.), Learning Analytics: Fundaments, Applications, and Trends (pp. 25-63). Springer.

Shute, V. J. (2008). Focus on formative feedback. Review of Educational Research, 78(1), 153-189. https://doi.org/10.3102/0034654307313795

Siemens, G., \& Gašević, D. (2012). Guest editorial: Learning and knowledge analytics. Journal of Educational Technology $\&$ Society, 15(3), 1-2.

Teo, T. (2010). Measuring the effect of gender on computer attitudes among pre-service teachers: A multiple indicators, multiple causes (MIMIC) modeling. Campus-Wide Information Systems, 27(4), 227-239. http://doi.org/10.1108/10650741011073770

Van Es, E. A., \& Sherin, M. G. (2002). Learning to notice: Scaffolding new teachers' interpretations of classroom interactions. Journal of Technology and Teacher Education, 10(4), 571-596. Retrieved from https://www.learntechlib.org/primary/p/9171/

Van den Bergh, L., Ros, A., \& Beijaard, D. (2013). Teacher feedback during active learning: Current practices in primary schools. British Journal of Educational Psychology, 83(2), 341-362. http://doi.org/10.1111/j.2044-8279.2012.02073.x

Van Den Bosch, R. M., Espin, C. A., Chung, S., \& Saab, N. (2017). Data-based decision-making: Teachers' comprehension of curriculum-based measurement progress-monitoring graphs. Learning Disabilities Research and Practice, 32(1), 46-60. https://doi.org/10.1111/ldrp.12122

Van Leeuwen, A., Janssen, J., Erkens, G., \& Brekelmans, M. (2014). Supporting teachers in guiding collaborating students: Effects of learning analytics in CSCL. Computers \& Education, 79, 28-39. https://doi.org/10.1016/j.compedu.2014.07.007

Van Leeuwen, A., Janssen, J., Erkens, G., \& Brekelmans, M. (2015). Teacher regulation of cognitive activities during student collaboration: Effects of learning analytics. Computers \& Education, 90, 80-94. https://doi.org/10.1016/j.compedu.2015.09.006

Van Leeuwen, A., \& Janssen, J. (2019). A systematic review of teacher guidance during collaborative learning in primary and secondary education. Educational Research Review, 27, 71-89. https://doi.org/10.1016/j.edurev.2019.02.001

Van Leeuwen, A., Rummel, N., \& van Gog, T. (2019). What information should CSCL teacher dashboards provide to help teachers interpret CSCL situations? International Journal of Computer-Supported Collaborative Learning, 14, 261289. https://doi.org/10.1007/s11412-019-09299-x

Venkatesh, V., Morris, M. G., Davis, G. B., \& Davis, F. D. (2003). User acceptance of information technology: Toward a unified view. MIS Quarterly, 27(3), 425-478. http://doi.org/10.2307/30036540

Verbert, K., Govaerts, S., Duval, E., Santos, J. L., Van Assche, F., Parra, G., \& Klerkx, J. (2014). Learning dashboards: An overview and future research opportunities. Personal and Ubiquitous Computing, 18(6), 1499-1514. https://doi.org/10.1007/s00779-013-0751-2

Verloop, N., Van Driel, J., \& Meijer, P. (2001). Teacher knowledge and the knowledge base of teaching. International Journal of Educational Research, 35(5), 441-461. https://doi.org/10.1016/S0883-0355(02)00003-4

Wise, A. F., \& Jung, Y. (2019). Teaching with analytics: Towards a situated model of instructional decision-making. Journal of Learning Analytics, 6(2). https://doi.org/10.18608/jla.2019.62.4

Wong, K.-T., Teo, T., \& Russo, S. (2012). Influence of gender and computer teaching efficacy on computer acceptance among Malaysian student teachers: An extended technology acceptance model. Australasian Journal of Educational Technology, 28(7), 1190-1207. https://doi.org/10.14742/ajet.796 
Xhakaj, F., Aleven, V., \& McLaren, B. M. (2017). Effects of a teacher dashboard for an intelligent tutoring system on teacher knowledge, lesson planning, lessons and student learning. Proceedings of the $12^{\text {th }}$ European Conference on Technology Enhanced Learning (EC-TEL 2017), 12-15 September 2017, Tallinn, Estonia (pp. 315-329). Lecture Notes in Computer Science. Springer, Cham. https://doi.org/10.1007/978-3-319-66610-5 23 